\title{
IMPLEMENTASI ALGORITMA DIJKSTRA UNTUK PENENTUAN JALUR TERPENDEK PADA APLIKASI EVAKUASI BENCANA UNTUK PENYANDANG DISABILITAS
}

\author{
Bahraen Folaimam ${ }^{1}$, Rosihan $^{2}$, Abdul Mubarak ${ }^{3}$ \\ Program Studi Teknik Informatika, Fakultas Teknik, Universitas Khairun \\ Jl.Jati Metro, Kota Ternate Selatan \\ E-mail :bahraenfolaimam88@gmail.com ${ }^{1}$,rosihan.unkhair@outlook.com², \\ abdulmubarak029@gmail.com ${ }^{3}$
}

\begin{abstract}
Persons with disabilities are people who have physical and socio-economic limitations so that they are very vulnerable when a disaster occurs, for this reason an application is needed that can provide location information and access roads to the evacuation team so that the evacuation process can be done quickly. One algorithm that can show the shortest path is the dijkstra algorithm. The workings of the dijkstra algorithm use a greedy strategy, where in each step the side with the smallest weight that connects a selected node with another node has not been selected. The purpose of this study is to implement the dijkstra algorithm for determining the shortest path in disaster evacuation applications and web-based dijkstra calculation system. The system is created using the Java programming language and PHP with prototype as a method of system development. The application is made using GPS technology to show the user's location. From the results of the comparison between disaster evacuation applications and web-based systems that both show the same shortest route only the distance weights are different. This is because the web-based system only uses the coordinates available in the database, while the disaster evacuation application is taken directly from the maps server. Thus the application of the dijkstra algorithm on the system will have a precise and accurate path if more specified coordinates.
\end{abstract}

\section{Keyword : Dijkstra, Prototype, GPS, Maps Server}

Abstrak -- Penyandang disabilitas merupakan orang yang memiliki keterbatasan fisik maupun sosial ekonomi sehingga sangat rentan ketika terjadi bencana, untuk itu dibutuhkan sebuah aplikasi yang dapat memberikan informasi lokasi dan akses jalan ke tim evakuasi agar proses evakuasi bisa dilakukan dengan cepat. Salah satu algoritma yang dapat menunjukan jalur terpendek adalah algoritma dijkstra. Cara kerja algoritma dijkstra memakai strategi greedy, dimana pada setiap langkah dipilih sisi dengan bobot terkecil yang menghubungkan sebuah simpul yang sudah terpilih dengan simpul lain yang belum terpilih. Tujuan dari penelitian ini adalah mengimplementasikan algoritma dijkstra untuk penentuan jalur terpendek pada aplikasi evakuasi bencana dan sistem perhitungan dijkstra berbasis web. Sistem dibuat dengan menggunakan bahasa pemrograman java dan PHP dengan prototype sebagai metode pengembangan sistemnya. Aplikasi dibuat dengan memanfaatkan teknologi GPS untuk menunjukan lokasi user. Dari hasil perbandingan antara aplikasi evakuasi bencana dan sistem berbasis web bahwa keduanya menunjukan rute terpendek yang sama hanya saja bobot jarak yang di tampilkan berbeda. Hal ini di karenakan pada sistem berbasis web hanya menggunakan koordinat yang tersedia di database, sedangkan pada aplikasi evakuasi bencana koordinatnya diambil langsung dari maps server. Dengan demikian penerapan algoritma dijkstra pada sistem akan memiliki jalur yang tepat dan akurat jika koordinat yang ditentukan semakin banyak.

Kata Kunci : Dijkstra, Prototype, GPS, Maps Server

\section{PENDAHULUAN}

Indonesia merupakan salah satu negara dengan tingkat kerawanan bencana yang tinggi dengan resiko korban yang tinggi pula [1]. Salah satu contoh daerah yang memiliki tingkat kerawanan bencana yang tinggi yaitu Ternate. Ternate memiliki gunung berapi Gamalama yang termasuk dalam kategori aktif, bencana yang ditimbulkan seperti gunung meletus, gempa, dan banjir lahar dingin [2].

Adanya bencana alam menyebabkan banyak korban baik luka maupun meninggal. Korban bisa siapa saja termasuk penyandang disabilitas.
Penyandang disabilitas sangat rentan saat terjadi bencana dikarenakan keterbatasan fisik maupun sosial ekonomi. Ketika bencana terjadi sering penyandang disabilitas tidak tanggap terhadap situasi darurat yang sedang terjadi. Perlu adanya pertolongan dari pihak yang berkompeten untuk membantu penyandang disabiltas dalam usaha evakuasi. Muncul permasalahan ketika penyandang disabilitas harus memberi informasi secara cepat dan akurat mengenai posisi mereka ke tim evakuasi karena keterbatasan yang dimiliki. Tidak menutup kemungkinan karena terlambatnya pemberian informasi tersebut dapat mengakibat korban luka atau sampai meninggal dunia. 
Untuk itu dibutuhkan suatu teknologi yang dapat memberikan informasi lokasi serta akses jalan yang harus di lalui pihak yang melakukan evakuasi sehingga kegiatan evakuasi dapat dilakukan secara cepat. Salah satu teknologi yang bisa digunakan adalah Location Based Service (LBS) yang mampu menyediakan layanan berbasis lokasi kepada pengguna mobile smartphone yang menerapkan sistem Global Positioning Satelite (GPS). Melalui teknologi LBS ini, maka perlu dikembangkan sebuah aplikasi yang mampu menyediakan informasi jalur evakuasi dengan menunjukkan rute terpendek.

Untuk menentukan rute terpendek diterapkan algoritma Dijkstra. Dari beberapa penelitian yang telah dilakukan sebelumnya terkait perbandingan algoritma penentuan jalur terpendek, algoritma Dijkstra memiliki kecepatan yang lebih cepat dalam memproses dari pada algoritma yang lain seperti algoritma A* (A Star), Algoritma Semut, dan Algoritma Bellman-Ford [3].

Berdasarkan latar belakang tersebut penulis melakukan sebuah penelitian dengan judul Implementasi Algoritma Dijkstra Untuk Penentuan Jalur Terpendek pada Aplikasi Evakuasi Bencana untuk Penyandang Disabilitas. Adanya aplikasi ini diharapkan dapat memberikan informasi lokasi penyandang disabilitas dengan teknologi GPS serta informasi akses jalan atau jalur terpendek menggunakan algoritma Dijkstra.

\section{TINJAUAN PUSTAKA}

\subsection{Android}

Android merupakan sistem operasi yang open source yang dibangun di atas Kernel Linux 2.6. Salah satu keuntungan dari sistem operasi open source ini yaitu aplikasi pihak ketiga (third-party application) dapat mengakses seluruh resource yang dimiliki oleh smartphone tersebut, tanpa membedakannya dengan aplikasi inti dari smartphone [4].

Pengembangan aplikasi android menggunakan bahasa pemrograman java yang mana konsep-konsep pemrograman java berhubungan dengan Object Oriented Programming (OOP). Selain itu pula dalam pengembangan aplikasi android membutuhkan Software Development Kit (SDK) yang disediakan android, SDK ini memberi jalan bagi programmer untuk mengakses Application Programming Interface (API) pada android [5]. Salah satu editor yang digunakan untuk pembuatan aplikasi berbasis android yaitu android studio.

\subsection{Disabilitas}

Istilah disabilitas secara terus menerus berkembang, baik itu pandangan maupun pendekatan pengembangannya. Terminologi yang digunakan juga berbeda pada tiap Negara dan wilayah. Ekspresi yang tidak sesuai atau bahkan menghina harus di hindari, meskipun jika hal tersebut masih digunakan pada instansi pemerintah. Disabilitas diartikan sebagai hasil dari interaksi antara orang dengan malfungsi organ tubuh, sikap, dan batasan lingkungan yang menghalangi mereka untuk secara penuh dan efektif berpartisipasi dalam masyarakat setara dengan orang lain. Malfungsi organ tubuh atau impairment adalah masalah pada fungsi tubuh atau struktur yang secara signifikan terganggu atau bahkan hilang, misalnya fungsi tubuh, fungsi mental, fungsi sensor dan rasa sakit, fungsi suara dan kemampuan berbicara, fungsi kardiovaskular, amputasi, ataupun penyakit-penyakit lainnya [1].

Berdasarkan hasil pengambilan data penyandang disabilitas yang dilakukan di Dinas Sosial Kota Ternate terdiri dari 840 orang, sedangkan di sekolah SLB Negeri Sasa Ternate dan s ekolah SLB YPAC Ternate terdiri 208 orang.

\subsection{Google Maps}

Google Maps adalah layanan oleh Google yang menawarkan teknologi pemetaan yang userfriendly. Layanan ini dapat diakses melalui situs http://maps.google.com atau http://maps.google.co.id untuk Google Maps Indonesia. Google Maps juga menawarkan peta yang dapat diseret dan gambar satelit untuk seluruh dunia, serta menawarkan rute perjalanan. Google Maps dibuat dengan menggunakan kombinasi dari gambar peta, database, serta objekobjek interaktif yang dibuat dengan bahasa pemrograman HTML, Javascript, dan AJAX, serta beberapa bahasa pemrograman lainnya. Seluruh citra yang ada diintegrasikan ke dalam suatu database pada google server [6].

\subsection{Global Positioning System (GPS)}

Global Positioning System (GPS) merupakan sebuah alat atau sistem yang dapat digunakan untuk menginformasikan penggunanya dimana lokasinya berada (secara global) di permukaan bumi yang berbasiskan satelit. Data di kirim dari satelit berupa sinyal radio dengan data digital. Dimanapun pengguna tersebut berada, maka GPS bisa membantu menunjukan arah. Awalnya GPS hanya digunakan hanya untuk kepentingan militer, tapi pada tahun 1980-an dapat digunakan untuk kepentingan sipil. GPS dapat di gunakan di manapun juga dalam 24 jam. Posisi unit GPS akan ditentukan berdasarkan titik-titik koordinat latitude dan longitude [7].

\subsection{Algoritma Dijkstra}

Algoritma ini dinamakan sesuai dengan nama penemunya, yaitu seorang ilmuwan komputer berkebangsaan Belanda yang bernama Edsger Dijkstra. Algoritma Dijkstra termasuk kedalam pembahasan teori graf pada matematika diskrit yang berhubungan dengan graf berbobot dan lintasan terpendek (shortest path). Algoritma ini digunakan untuk mencari lintasan terpendek pada sebuah graf berarah. Cara kerja algoritma Dijkstra memakai stategi greedy, dimana pada setiap langkah dipilih sisi dengan bobot terkecil yang menghubungkan sebuah simpul yang sudah terpilih dengan simpul lain yang belum terpilih [8]

Algoritma yang ditemukan oleh Dijkstra untuk mencari path terpendek merupakan algoritma yang 
lebih efisien dibandingkan algoritma Warshall, meskipun implementasinya juga lebih sukar. Misalkan $\mathrm{G}$ adalah graf berarah berlabel dengan titik-titik $\mathrm{V}(\mathrm{G})$ $=\{\mathrm{v} 1, \mathrm{v} 2, \ldots, \mathrm{vn}\}$ dan path terpendek yang dicari adalah dari v1 ke vn. Algoritma Dijkstra dimulai dari titik v1. Dalam iterasinya, algoritma akan mencari satu titik yang jumlah bobotnya dari titik 1 terkecil. Titiktitik yang terpiih dipisahkan dan titik-titik tersersebut tidak diperhatikan lagi dalam iterasi berikutnya.

Misalkan:

$\begin{array}{lll}\mathrm{V}(\mathrm{G})= & = & \text { Himpunan titik-titik } \varepsilon \mathrm{V}(\mathrm{G}) \text { yang } \\ \{\mathrm{v} 1, \mathrm{v} 2, . ., & & \text { sudah terpilih dalam jalur path } \\ \mathrm{vn}\} \mathrm{L} & \text { terpendek. } \\ \mathrm{D}(\mathrm{j}) & \text { Jumlah bobot path terkecil dari v1 } \\ & \text { ke vj. } \\ \mathrm{w}(\mathrm{i}, \mathrm{j}) & \text { Bobot garis dari titik vi ke vj. } \\ \mathrm{w}^{*}(1, \mathrm{j}) & = & \text { Jumlah bobot path terkecil dari v1 } \\ & \text { ke } \mathrm{vj}\end{array}$

Menurut algoritma di atas, path terpendek dari titik v1 ke vn adalah melalui titik-titik dalam L secara berurutan, dan jumlah bobot path terkecilnya adalah $\mathrm{D}(\mathrm{n})$. Untuk menghitung weight (bobot ) nilai minimum menggunakan persamaaan berikut [8].

Weight $(\mathrm{w})=\min$ (DastValue, MarkValue +

EdgeValue)..............................................(1)

Dimana : DastValue $=$ Nilai dalam node tujuan MarkValue = Nilai dalam node awal

EdgeValue $=$ Bobot dari sisi yang menghubungkan node

\subsection{Metode Prototype}

Prototype merupakan metodologi pengembangan software yang menitik beratkan pada pendekatan aspek desain, fungsi dan user-interface. Developer dan user fokus pada user-interface dan bersama-sama mendefinisikan spesifikasi, fungsi, desain dan bagaimana software bekerja. Developer dan user bertemu dan melakukan komunikasi dan menentukan tujuan umum, kebutuhan yang diketahui dan gambaran bagian-bagian yang akan dibutuhkan. [9].

Cakupan aktivitas dari prototyping model terdiri dari:

1. Mendefinisikan objektif secara keseluruhan dan mengidentifikasi kebutuhan yang sudah diketahui.

2. Melakukan perancangan secara cepat sebagai dasar untuk membuat prototype.

3. Menguji coba dan mengevaluasi prototype dan kemudian melakukan penambahan dan perbaikanperbaikan terhadap prototype yang sudah dibuat.

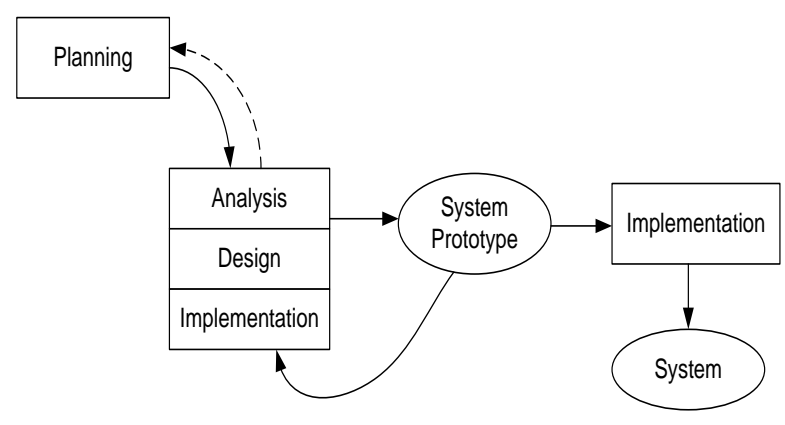

Gambar 1. Prototyping Model [9]

III. METODE PENELITIAN

Pada penelitian ini metode pengembangan perangkat lunak yang digunakan adalah metode prototype yaitu sebagai berikut.

\subsection{Analisis}

Tahapan pengumpulan data yang dilakukan adalah sebagai berikut.

1.1 Observasi

Observasi yaitu pengamatan langsung ke beberapa lokasi penyandang disabilitas untuk melihat bagaimana kondisi penyandang disabilitas serta untuk mengetahui langsung seperti apa aktivitas dari penyandang disabilitas.

1.2 Wawancara

Wawancara (Interview), dengan cara tanya jawab dengan Badan Penanggulangan Bencana Daerah (BPBD) Ternate dan Komunitas Relawan Bencana Maluku Utara tentang apa saja kendala yang dihadapi saat proses penanganan yang dilakukan terhadap para penyandangan disabilitas ketika akan atau saat terjadi bencana.

\subsection{Desain Sistem}

1. Diagram UML

Pada tahap ini akan dilakukan pemodelan sistem untuk keperluan proses dan dokumentasi, perancangan UML seperti diagram use case yaitu use case untuk tim evakuasi dan use case untukdisabilitas atau wali, diagram activity, perancangan tabel database, dan perancangan antarmuka pengguna dari aplikasi evakuasi bencana berbasis android.

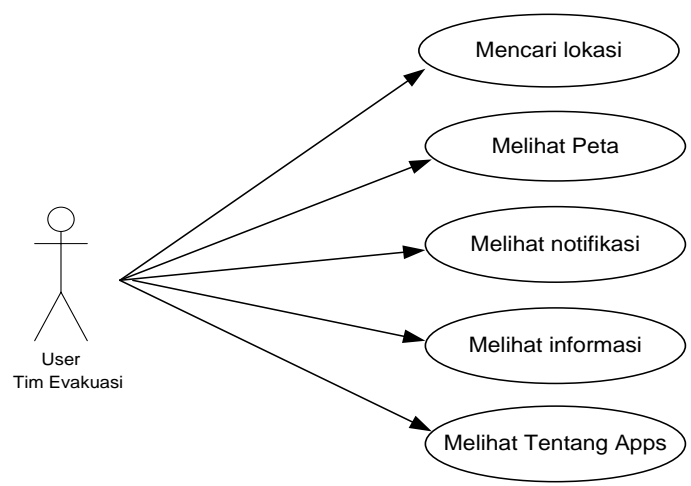

Gambar 2 Use Case User (Tim Evakuasi)

\section{Diagram Activity}




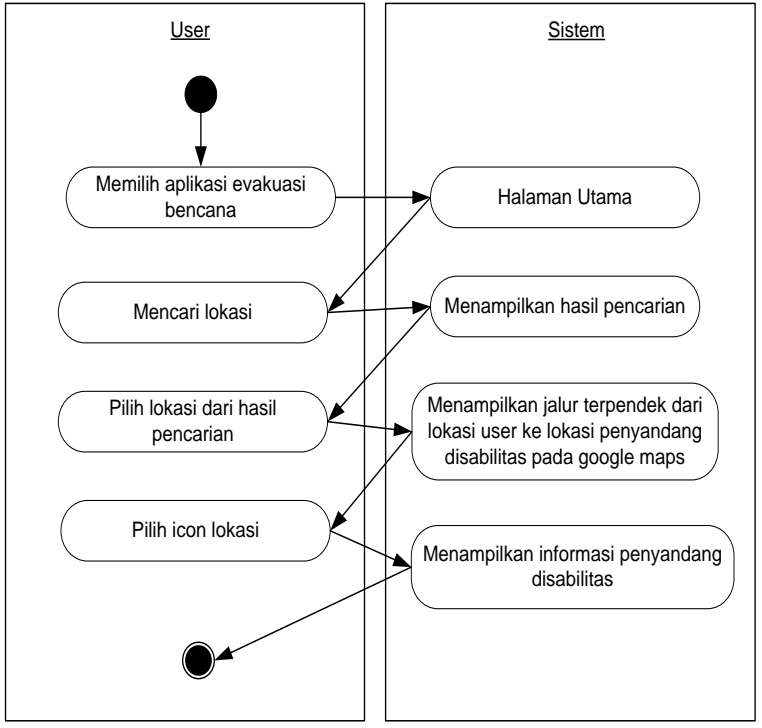

Gambar 3 Diagram Activity User Melihat Lokasi Penyandang Disabilitas
1. User memilih aplikasi evakuasi bencana untuk penyandang disabilitas

2. Sistem menampilkan tampilan menu utama yang terdapat beberapa menu atau button seperti location search, maps, login dan about. User memilih menu pencarian koordinat lokasi

3. Sistem merespon pencarian lokasi dengan menampilkan lokasi sesuai pilihan user dalam bentuk peta google maps, sekaligus menampilkan jalur terpendek dari lokasi user ke lokasi penyandang disabilitas.

4. Setelah itu jika user ingin melihat informasi mengenai penyandang disabilitas, user dapat memilih icon lokasi penyandang disabilitas pada maps.

3. Diagram Blok

Berikut ini merupakan diagram blok aplikasi evakuasi bencana untuk penyandang disabilitas berbasis android.

Keterangan :

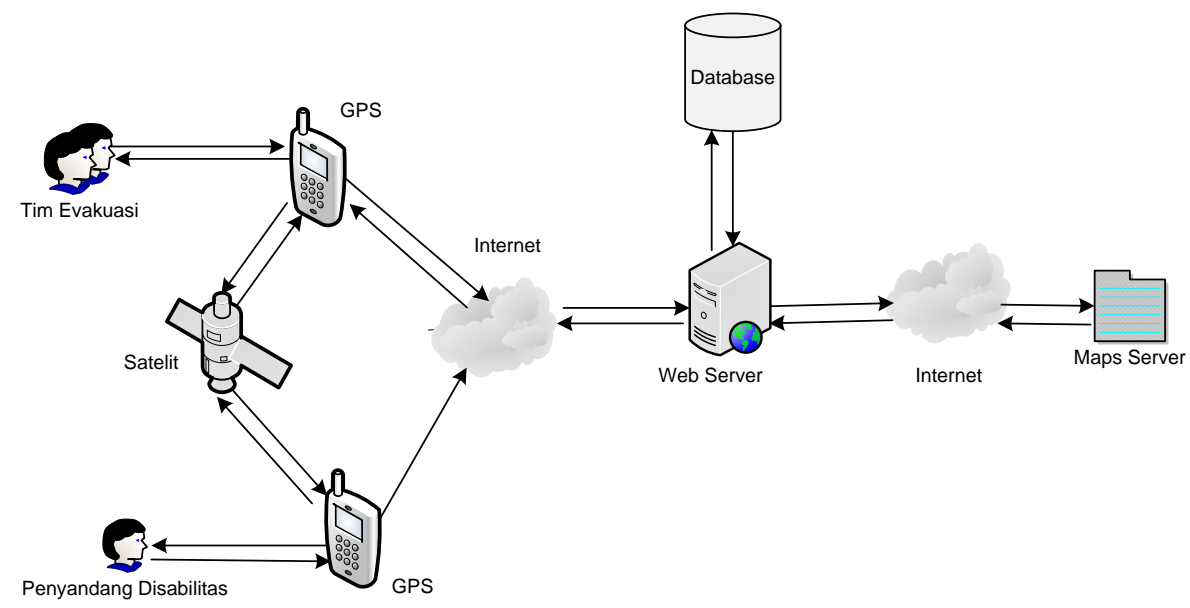

Gambar 3 Diagram Blok Sistem Evakuasi Bencana Untuk Penyandang Disabilitas

Sistem yang dibuat terdiri dari aplikasi evakuasi bencana, web server dan database yang saling terhubung. Database yang digunakan yaitu MySQL yang berisi data user (penyandang disabilitas). Perangkat android akan berkomunikasi dengan database untuk memanggil maupun menyimpan data. Selain itu perangkat android juga akan terhubung dengan google maps serta terhubung dengan satelit GPS. GPS berguna sebagai tracking dan memberi tahukan lokasi user (penyandang disabilitas) ke user (tim evakuasi). Untuk penentuan rute terpendek diambil langsung dari server google maps yang algoritma default penentuan jalurnya menggunakan algoritma djikstra. Nantinya pada aplikasi evakuasi akan dibuat sebuah class java yang akan menerima input-an berupa dua buah koordinat, titik awal dan titik tujuan. Untuk kemudian di decode menggunakan Google Maps APIs, yang menghasilkan sebuah file XML. Kemudian XML tersebut akan diubah menjadi sebuah ArrayList berisi LatLng (titik koordinat latitude dan longitude).

\section{HASIL DAN PEMBAHASAN}

Pada bab ini menjelaskan tentang hasil implementasi dari perancangan aplikasi pada bab sebelumnya. Hasil yang di bahas berupa fitur aplikasi dan interfaces yang terdapat di dalam aplikasi penentuan jalur terpendek untuk evakuasi bencana menggunakan algoritma dijkstra. Selain itu pada bab ini juga akan dijelaskan mengenai hasil uji coba terhadap aplikasi penentuan jalur terpendek untuk evakuasi bencana menggunakan algoritma dijkstra yang telah dibuat.

\section{Impementasi Interfaces}

Dalam aplikasi penentuan jalur terpendek untuk evakuasi bencana menggunakan algoritma dijkstra ini mengimplemtasikan beberapa interfaces.

a. Halaman Utama

Setelah itu aplikasi akan menampilkan halaman menu utama, pada halaman menu utama terdapat beberapa pilihan button yaitu Login, Search Location, Maps dan About Apps. Pada gambar 4 merupakan 
tampilan aplikasi.

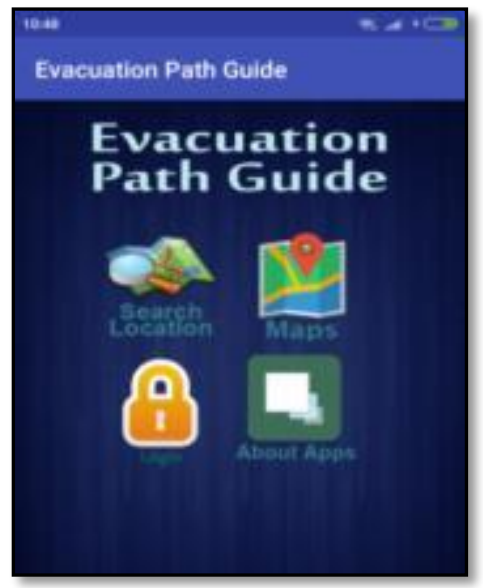

Gambar 5 Halaman Utama

\section{b. Halaman Login}

Pada gambar 6 dapat di tampilan aplikasi yang menunjukan user (penyandang disabilitas/wali) dapat melakukan login dan registrasi.

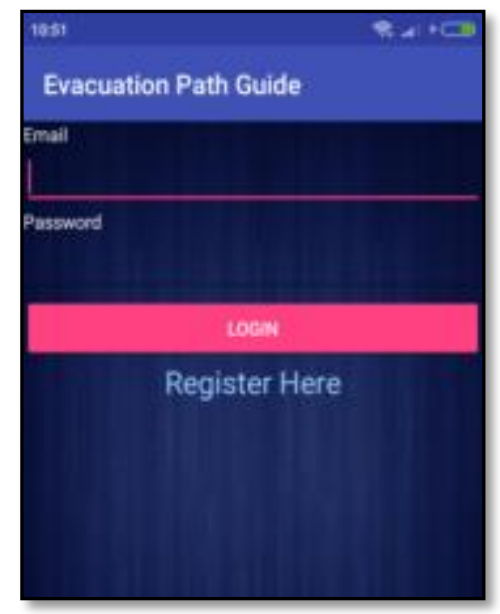

Gambar 6 Halaman Login

\section{c. Halaman Register}

Jika user melakukan registrasi maka aplikasi akan menampilkan alert dialog untuk memasukkan biodata user lalu klik daftar seperti gambar 7 .

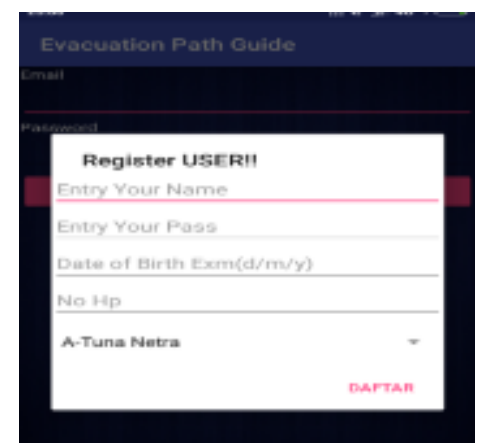

d. Halaman Button Panic

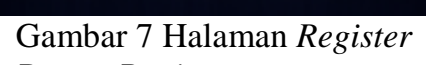

Jika pengguna sudah berhasil melakukan register maka akun tersebut dapat digunakan untuk login ke aplikasi, jika berhasil login maka pengguna akan menampilkan halaman butto panic yang fungsinya koordinat jalur lokasi. jika user (penyandang disabilitas) berada dalam keadaan darurat pengguna dapat menekan tombol tersebut maka secara otomatis aplikasi akan membagikan lokasi keberadaannya ke tim evakuasi. Seperti pada gambar 8 .

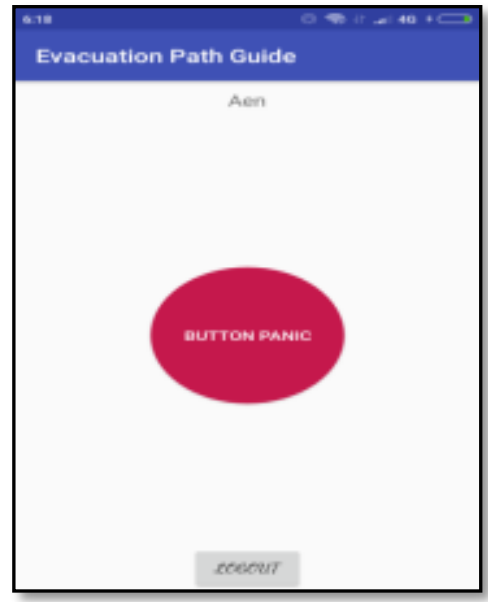

Gambar 8 Halaman Button Panic

e. Menampilkan Rute Terpendek

Apabila pengguna disabilitas berada dalam kondisi darurat dam sudah menekan button panic maka tim evakuasi secara otomatis menerima koordinat lokasi disablitas dan secara langsung menampilkan jalur terpendek pada maps, seperti pada gambar 9 .

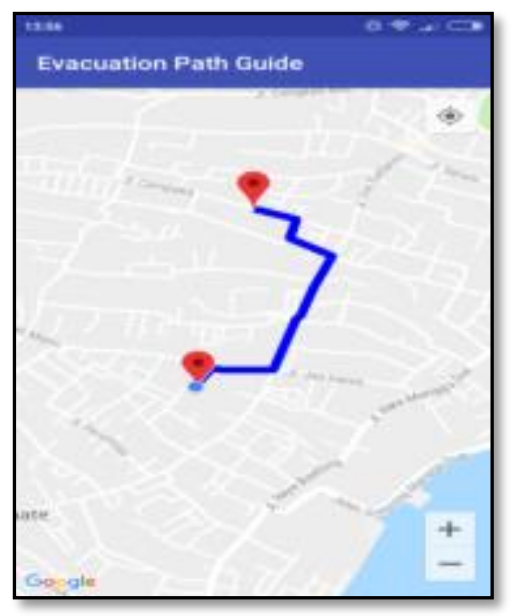

Gambar 9 Rute Terpendek pada Maps

\section{Implementasi Interfaces Pada Sistem Perhitungan Dijkstra Berbasis Web}

Pada gambar 10 merupakan rancangan titik-titik koordinat lokasi yang di ambil dari google maps dan diterapakan di dalam sistem. Titik koordinat jalur yang diterpakan bobot jarak masing-masing dalam satuan meter. Untuk koordinat jalur beserta bobot jarak diambil dengan memanfaatkan sebuah situs maps yaitu graplatcoding.com yang dibuat khusus untuk mempermudah dalam mendapatkan data-data 


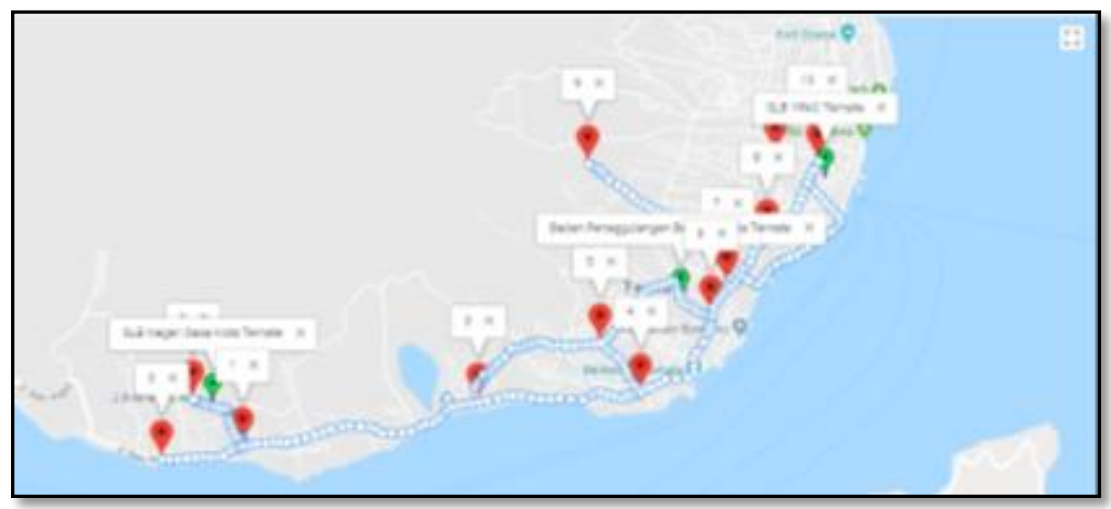

Gambar 10 Titik-titik Koordinat Lokasi

Tabel 1 Tabel Jalur Pada Database

\begin{tabular}{|c|c|c|}
\hline Id & No_Trayek & Simpul \\
\hline 1 & J01 & $\begin{array}{l}0-1,1-3,3-4,4-6,6-7,7-8,8-10,10- \\
8,8-7,7-6,6-4,4-3,3-1,1-0,\end{array}$ \\
\hline 2 & $\mathrm{~J} 02$ & $1-2,2-1$ \\
\hline 3 & $\mathrm{~J} 03$ & $3-5,5-6,6-5,5-3$ \\
\hline 4 & $\mathrm{~J} 04$ & $5-4,4-5$ \\
\hline 5 & $\mathrm{~J} 05$ & $8-9,9-8$ \\
\hline 6 & J06 & $7-10,10-7$ \\
\hline
\end{tabular}

Pada tabel 1 menunjukan simulasi jalur-jalur yang sudah di sediakan di dalam database. Pada kolom "No_Trayek" menunjukan nama jalur yang terdiri dari 6 jalur yaitu J01, J02, J03, J04, J05 dan J06. Dari setiap jalur terdapat "Simpul" yang ditandai dalam bentuk angka-angka. Angka-angka tersebut menunjukan nama jalan yang di lalui, diberi simbol dengan angka agar dalam implementasi ke sistem lebih mudah.

Pseudocode algoritma Dijkstra

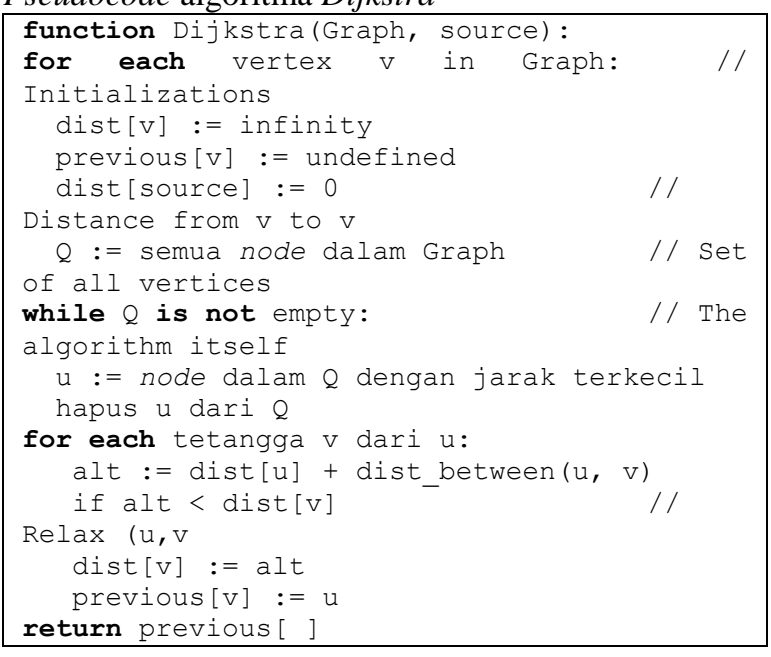

\section{Pengujian}

Pada tahap ini aplikasi yang sudah dibuat akan dilakukan ujicoba untuk memastikan bahwa aplikasi berjalan sesuai perancangan dan algoritmanya pun berjalan dengan benar. Pengujian yang dilakukan terdiri dari 2 yaitu sebagai berikut.

a. Pengujian Sistem

Pengujian sistem dilakukan menggunakan metode yang blackbox untuk mengamati dan mengetahui keluaran dari berbagai masukkan, jika aplikasi evakuasi bencana telah sesuai dengan perancangan untuk variasi data, maka sistem tersebut dinyatakan baik.

Tabel 2 Tabel Pengujian Register Aplikasi

\begin{tabular}{|c|c|c|c|}
\hline \multicolumn{4}{|c|}{ Hasil Uji Data Normal } \\
\hline $\begin{array}{c}\text { Data } \\
\text { Masukkan } \\
\end{array}$ & $\begin{array}{c}\text { Yang } \\
\text { Diharapkan } \\
\end{array}$ & Pengamatan & $\begin{array}{c}\text { Kesimpula } \\
\mathrm{n}\end{array}$ \\
\hline $\begin{array}{l}\text { Input data } \\
\text { registrasi }\end{array}$ & $\begin{array}{l}\text { Menampilkan } \\
\text { data } \\
\text { konfirmasi }\end{array}$ & $\begin{array}{l}\text { Hasil sesuai } \\
\text { dengan } \\
\text { yang } \\
\text { diharapkan }\end{array}$ & Diterima \\
\hline $\begin{array}{l}\text { GPS Aktif } \\
\text { saat } \\
\text { registrasi }\end{array}$ & $\begin{array}{l}\text { Menampilkan } \\
\text { koordinat } \\
\text { Lokasi }\end{array}$ & $\begin{array}{l}\text { Hasil sesuai } \\
\text { dengan } \\
\text { yang } \\
\text { diharapkan }\end{array}$ & Diterima \\
\hline \multicolumn{4}{|c|}{ Hasil Uji (Data Tidak Normal) } \\
\hline $\begin{array}{l}\text { GPS tidak } \\
\text { aktif saat } \\
\text { registrasi }\end{array}$ & $\begin{array}{l}\text { Muncul pesan } \\
\text { "Please } \\
\text { enable GPS" }\end{array}$ & $\begin{array}{l}\text { Hasil sesuai } \\
\text { dengan } \\
\text { yang } \\
\text { diharapkan }\end{array}$ & Diterima \\
\hline
\end{tabular}

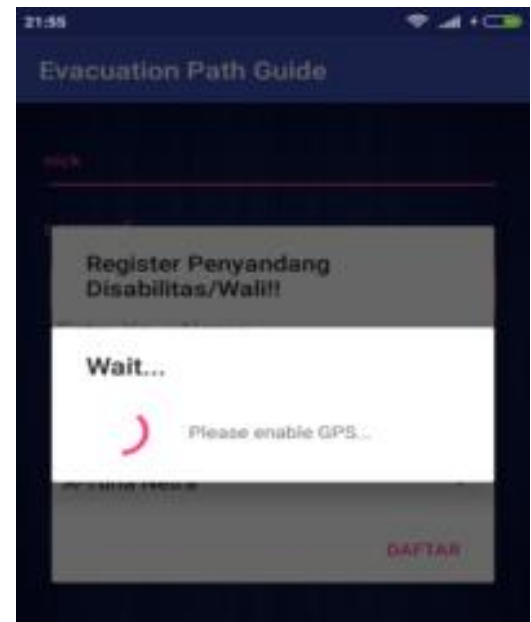

Gambar 11 GPS Tidak Aktif Saat Registrasi

Tabel 3 Tabel Pengujian Login Aplikasi

\begin{tabular}{|c|c|c|c|}
\hline \multicolumn{4}{|c|}{ Hasil Uji Data Normal } \\
\hline $\begin{array}{c}\text { Data } \\
\text { Masukkan }\end{array}$ & $\begin{array}{c}\text { Yang } \\
\text { Diharapkan }\end{array}$ & Pengamatan & Kesimpulan \\
\hline $\begin{array}{l}\text { Username } \\
\text { : aen } \\
\text { Password }\end{array}$ & $\begin{array}{l}\text { Menampilka } \\
\mathrm{n} \text { halaman } \\
\text { button panic }\end{array}$ & $\begin{array}{l}\text { Hasil sesuai } \\
\text { dengan yang } \\
\text { diharapkan }\end{array}$ & \\
\hline
\end{tabular}


Implementasi Algoritma Dijkstra Untuk Penentuan Jalur Terpendek Pada Aplikasi Evakuasi Bencana Untuk Penyandang Disabilitas

\begin{tabular}{|c|c|c|c|}
\hline \multicolumn{4}{|c|}{ Hasil Uji Data Normal } \\
\hline $\begin{array}{c}\text { Data } \\
\text { Masukkan }\end{array}$ & $\begin{array}{c}\text { Yang } \\
\text { Diharapkan }\end{array}$ & Pengamatan & Kesimpulan \\
\hline : aen & & & \\
\hline \multicolumn{4}{|c|}{ Hasil Uji (Data Tidak Normal) } \\
\hline $\begin{array}{l}\text { Username } \\
\text { : bahraen } \\
\text { Password } \\
\text { : bahraen }\end{array}$ & $\begin{array}{l}\text { Muncul } \\
\text { pesan "login } \\
\text { failed", }\end{array}$ & $\begin{array}{l}\text { Hasil sesuai } \\
\text { dengan yang } \\
\text { diharapkan }\end{array}$ & Diterima \\
\hline $\begin{array}{l}\text { User dan } \\
\text { password } \\
\text { belum } \\
\text { dikonfirm } \\
\text { asi oleh } \\
\text { admin }\end{array}$ & $\begin{array}{l}\text { Muncul } \\
\text { pesan "login } \\
\text { failed" }\end{array}$ & $\begin{array}{l}\text { Hasil sesuai } \\
\text { dengan yang } \\
\text { diharapkan }\end{array}$ & Diterima \\
\hline $\begin{array}{l}\text { GPS tidak } \\
\text { aktif saat } \\
\text { login }\end{array}$ & $\begin{array}{l}\text { Muncul } \\
\text { pesan } \\
\text { "Please } \\
\text { enable } \\
\text { GPS" }\end{array}$ & $\begin{array}{l}\text { Hasil sesuai } \\
\text { dengan yang } \\
\text { diharapkan }\end{array}$ & Diterima \\
\hline
\end{tabular}

\begin{tabular}{|l|l|l|c|}
\hline \multicolumn{4}{|c|}{ Hasil Uji Data Normal } \\
\hline $\begin{array}{c}\text { Data } \\
\text { Masukkan }\end{array}$ & \multicolumn{1}{|c|}{$\begin{array}{c}\text { Yang } \\
\text { Diharapkan }\end{array}$} & Pengamatan & $\begin{array}{c}\text { Kesimpula } \\
\mathrm{n}\end{array}$ \\
\hline $\begin{array}{l}\text { Pilih } \\
\text { lokasi di } \\
\text { listview }\end{array}$ & $\begin{array}{l}\text { Menampilkan } \\
\text { maps dan } \\
\text { lokasi sesuai } \\
\text { pilihan }\end{array}$ & $\begin{array}{l}\text { Hasil sesuai } \\
\text { dengan yang } \\
\text { diharapkan }\end{array}$ & Diterima \\
\hline $\begin{array}{l}\text { Koneksi } \\
\begin{array}{l}\text { Internet \& } \\
\text { GPS aktif }\end{array}\end{array}$ & $\begin{array}{l}\text { Menampilkan } \\
\text { rute terpendek } \\
\text { pada maps }\end{array}$ & $\begin{array}{l}\text { Hasil sesuai } \\
\text { dengan yang } \\
\text { diharapkan }\end{array}$ & \\
\hline \multicolumn{4}{|c|}{ Hasil Uji (Data Tidak Normal) } \\
\hline $\begin{array}{l}\text { Koneksi } \\
\text { Internet } \\
\text { Buruk }\end{array}$ & $\begin{array}{l}\text { Rute di maps } \\
\text { tidak tampil }\end{array}$ & $\begin{array}{l}\text { Hasil sesuai } \\
\text { dengan yang } \\
\text { diharapkan }\end{array}$ & Diterima \\
\hline
\end{tabular}

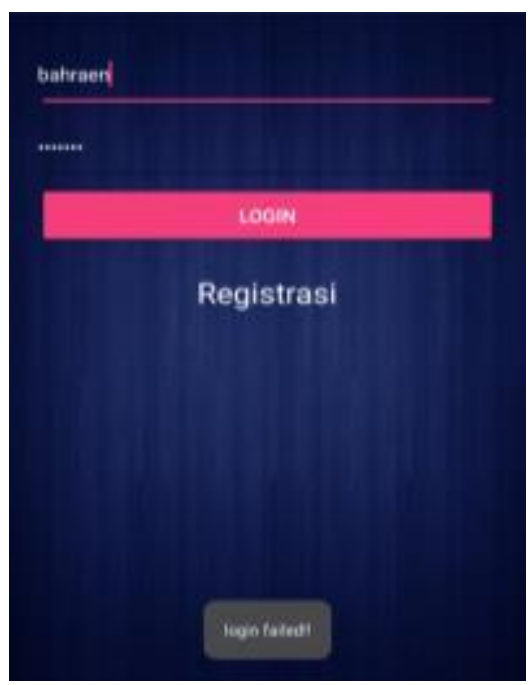

Gambar 12 Login Failed

Tabel 4 Tabel Pengujian Listview dan Maps

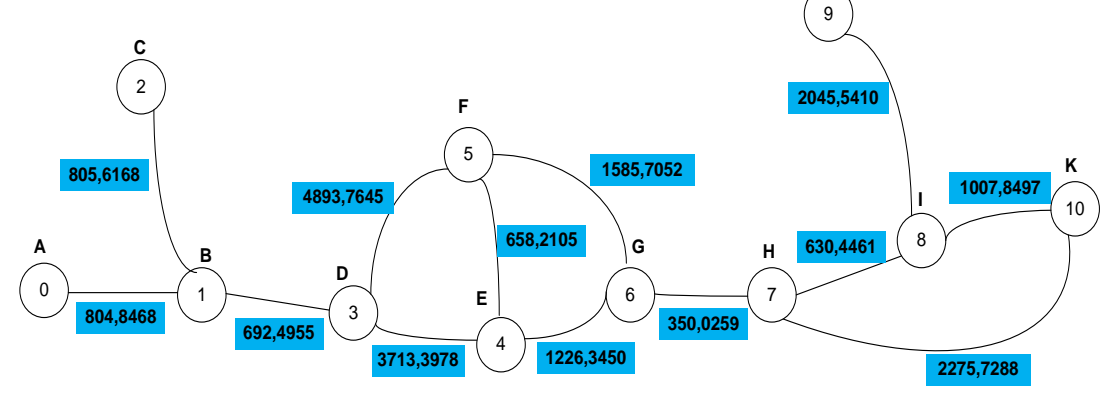

Ket :

Jarak antar tempat dengan satuan meter

$\bigcirc$ Node/Tempat

Gambar 14 Titik-titik Koordinat Lokasi

Tabel 5 Pengujian Algoritma Dijkstra Pengujian 1

Koordinat Awal Kampus Jati (J) : $0.7759705,127.3732416$

\begin{tabular}{|l|}
\hline \multicolumn{2}{|c|}{ Koordinat Tujuan SLB Negeri Sasa Kota Ternate } \\
(C) $: 0.75526,127.32484$ \\
\hline $\begin{array}{l}\text { Relasi Vertex } 1: \text { J-I-H- } \\
\text { G-F-D-B-C }\end{array}$ \\
\hline
\end{tabular}




\begin{tabular}{|c|c|}
\hline $\begin{array}{l}\text { Relasi Vertex } 2: \mathrm{J}-\mathrm{I}-\mathrm{H}- \\
\text { G-E-F-D-B-C }\end{array}$ & 11302,4453 meter \\
\hline $\begin{array}{l}\text { Relasi Vertex } 3: \mathrm{J}-\mathrm{I}-\mathrm{H}- \\
\text { G-E-D-B-C }\end{array}$ & 9463,8681 meter \\
\hline
\end{tabular}

Pada tabel 5 dapat di lihat hasil pengujian algoritma dijkstra secara manual (menggunakan excel) dengan rute terpendek dari $\mathrm{J}$ ke $\mathrm{C}$ yang diperoleh adalah pada relasi vertex $3=\mathrm{J}-\mathrm{I}-\mathrm{H}-\mathrm{G}-\mathrm{E}-\mathrm{D}-$ B-C dengan bobot atau jarak 9463,8681 meter. Untuk rute terpendeknya dapat dilihat pada gambar 4.33 yang ditandai dengan garis berwarna merah.
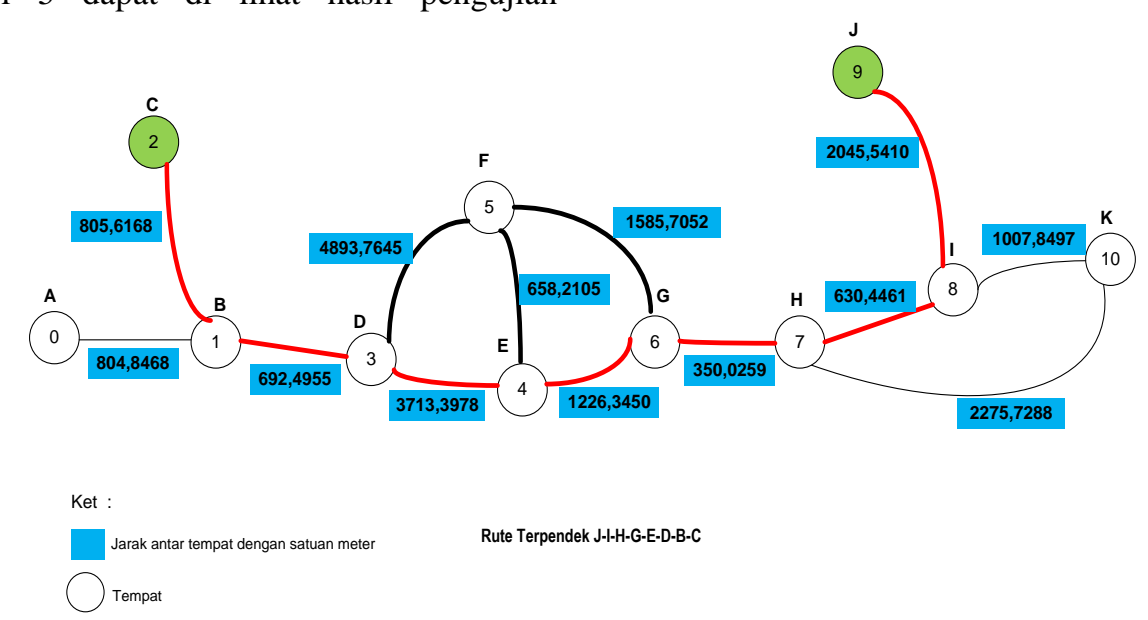

Rute Terpendek J-I-H-G-E-D-B-C

Gambar 15 Rute Terpendek

Tabel 6 Tabel Jalur di Maps

\begin{tabular}{|c|c|c|}
\hline $\begin{array}{c}\text { Nama Jalan } \\
\text { dalam Bentuk } \\
\text { Huruf }\end{array}$ & $\begin{array}{c}\text { Nama Jalan dalam } \\
\text { Bentuk Angka di } \\
\text { Maps }\end{array}$ & $\begin{array}{c}\text { Nama } \\
\text { Jalur di } \\
\text { Maps }\end{array}$ \\
\hline J - I & $9-8$ & J05 \\
\hline I - H & $8-7$ & J01 \\
\hline H - G & $7-6$ & J01 \\
\hline G - E & $6-4$ & J01 \\
\hline E - D & $4-3$ & J01 \\
\hline D - B & $3-1$ & J01 \\
\hline B - C & $1-2$ & J02 \\
\hline
\end{tabular}

Untuk hasil perhitungan dijkstra pada sistem berbasis web dapat dilihat pada gambar 16 .

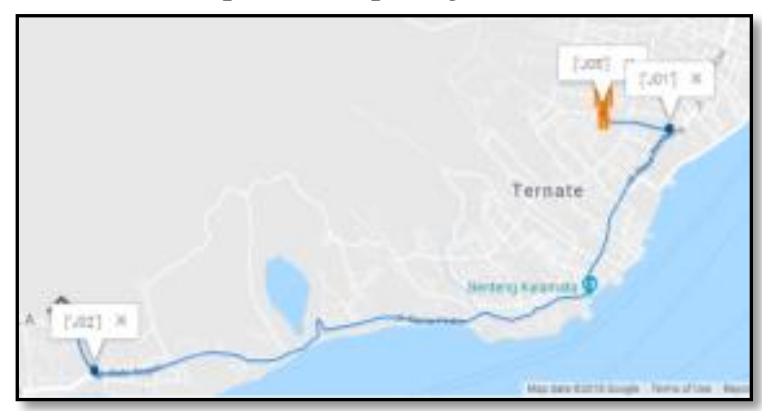

Gambar 16 Rute Terpendek pada Maps (J05-J01-J02)

Sedangkan untuk tampilan rute terpendek pada

\section{Analisis Hasil Pengujian}

Bedasarkan pengujian yang telah dilakukan yaitu pengujian sistem dengan metode blackbox menunjukan bahwa aplikasi evakuasi bencana yang dibuat terdiri dari 4 mепи yaitu halaman login, maps, about, dan search location, selain itu lokasi pengguna yang di tampilkan pada maps dapat di tampilkan dengan memanfaatkan GPS smartphone, aplikasi dapat terkoneksi dengan database server sehingga dapat melakukan penyimpanan maupun pengambilan data. Dengan demikian maka aplikasi evakuasi bencana sudah berjalan sesuai dengan perancangan sistem.

Untuk pengujian algoritma yang di lakukan pada sistem berbasis web dapat di implemtasikan algoritma dijkstra dan mampu menunjukan rute terpendek menuju lokasi tujuan, hanya saja pada sistem berbasis web lokasi tujuannya sudah ditetapkan di dalam database sedangkan lokasi awal di tetapkan sendiri oleh pengguna tanpa menggunakan GPS. Dengan demikian jika di lakukan zoom out pada maps yang terdapat pada sistem maka terlihat titik koordinat awal yang di ambil untuk perhitungan dijkstra tidak sesuai dengan posisi user melainkan yang diambil adalah koordinat yang berdekatan dengan posisi user kecual jika posisi user tepat berda pada jalur yang sudah di tetapkan.

Dari pengujian tersebut di simpulkan bahwa perhitungan algoritma dijkstra hanya dapat dilakukan pada koordinat-koordinat lokasi yang sudah ada di dalam database jika ada koordinat lokasi baru yang tidak ada di dalam database maka sistem akan mengambil koordinat yang terdekat dengan koordinat baru tersebut. Berbeda dengan aplikasi evakuasi bencana yang menunujakan rute terpendek langsung dari titik awal dan tujuan, hal ini di karenakan koordinat jalur di ambil dari google maps API sehingga semua koordinat lokasi sudah tersedia.

\section{PENUTUP}

\section{Kesimpulan}

Berdasarkan hasil penelitian yang telah di lakukan dengan mengimplemantasikan algoritma dijkstra pada aplikasi evakuasi bencana dan sistem berbasis web 
untuk pencarian rute terpendek dapat di simpulkan bahwa :

1. Pembuatan aplikasi evakuasi bencana pada platform android dapat dilakukan dengan menggunakan bahasa pemrograman java dengan memanfaatkan android studio sebagai Integrated Development Environment (IDE). Pembuatan basis data juga dapat dilakukan dengan memanfaatkan dua database yaitu android SQLite sever dan MySQL dengan koneksinya menggunakan PHP.

2. Metode pengembangan perangkat lunak prototype dapat digunakan untuk pengembangan aplikasi evakuasi bencana yang terdiri dari beberapa tahapan yaitu analisis di mana dilakukan analisis tentang proses penanganan penyandang disablitas ketika proses evakuasi bencana. Desain sistem dilakukan mulai dari perancangan UML, basisdata sampai pada perancangan interfaces. Pengkodean, dimana desain sistem dikonversi ke bahasa pemgrograman dan terakhir yaitu pengujian sistem dengan menggunakan blackbox.

3. Pemanfaatan GPS pada aplikasi evakuasi bencana dapat diimplementasikan sehingga mempermudah aplikasi untuk mendeteksi titik koordinat lokasi user.

4. Berdasarkan hasil perbandingan algoritma dijkstra diantara aplikasi evakuasi bencana dan sistem berbasis web bahwa keduanya menunjukan rute terpendek yang sama dengan bobot jarak yang berbeda. Hal ini di karenakan pada sistem

\section{Saran}

Dari pembuatan aplikasi evakuasi bencana sampai dengan hasil dan pengujiannya masih memiliki banyak kekurangan, untuk itu ada beberapa saran yang dapat diberikan penulis yaitu:

1. Dari hasil di atas perlu di adakan penelitian yang lebih lanjut untuk memaksimalkan fungsi aplikasi evakuasi bencana dengan penambahan fitur yang dapat menampilkan jarak dan waktu tempuh dari lokasi awal ke lokasi tujuan.

2. Ada sekitar 11 jenis penyandang disabilitas dengan keterbatasan yang berbeda-beda maka tidak semua penyandang disabilitas dapat menggunakan aplikasi ini sehingga memungkinkan penggunaan aplikasi masih harus digunakan dengan bantuan wali, untuk itu pada penelitian selanjutnya hal ini bisa dijadikan sebagai bahan pertimbangan.

3. Untuk lebih memaksimalkan proses evakuasi aplikasi masih perlu ditambahkan titik-titik jalur evakuasi agar lebih mempermudah tim evakuasi dalam melakukan proses evakuasi.

\section{DAFTAR PUSTAKA}

[1] R. Probosiwi, "Keterlibatan Penyandang Disabilitas Dalam Penanggulangan Bencana," vol. 4, hal. 13-22, 2013.

[2] S. J. Kesdm, A. Febriani, C. P. Sari, dan D.
Ester, "Kementerian Energi Dan Sumber Daya Mineral," 2015. [Daring]. Tersedia pada: http://vsi.esdm.go.id. [Diakses: 22-Sep-2017].

[3] M. S. Handaka, "Perbandingan Algoritma Dijkstra ( Greedy), Bellman-Ford ( BFS-DFS ), dan Floyd-Warshall ( Dynamic Programming) dalam Pengaplikasian Lintasan Terpendek pada Link-State Routing Protocol," informatika, hal. $1-8,2011$.

[4] B. R. Rompas, "Aplikasi Location-Based Service Pencarian Tempat Di Kota Manado Berbasis Android," no. 1, hal. 1-11, 2013.

[5] U. Hasanah, N. Safriadi, dan Tursina, "Location Based Service Lokasi Masjid Pontianak Menggunakan Metode Dijkstra Berbasis Android," J. Sist. dan Teknol. Inf., hal. 1-6, 2015.

[6] N. Muslim dan A. Sunyoto, "Sistem Informasi Geografis Berbasis Pemetaan Potensi Panas Bumi Di Indonesia Menggunakan Google Maps," J. Dasi, vol. 13, no. 2, hal. 60-64, 2012.

[7] F. Mahdia dan F. Noviyanto, "Pemanfaatan Google Maps API untuk Pembangunan Sistem Informasi Manajemen Bantuan Logistik Pasca Bencana Alam Berbasis Mobile Web," J. Sarj. Tek. Inform., vol. 1, no. 1, hal. 162-171, 2013.

[8] Fitria dan A. Triansyah, "Implementasi Algoritma Dijkstra Dalam Aplikasi Untuk Menentukan Lintasan Terpendek Jalan Darat Antar Kota Di Sumatera Bagian Selatan," J. Sist. Inf., vol. 5, no. 2, hal. 611-621, 2013.

[9] D. S. Budi, T. A. Y. Siswa, dan H. Abijono, "Analisis Pemilihan Penerapan Proyek Metodologi Pengembangan Rekayasa Perangkat Lunak," Teknika, vol. 5, no. November, hal. 2431, 2016. 